\title{
HORMONAL ANTAGONISM TO THE ANTISPERMATOGENIC EFFECT OF ETHYLENE- DIMETHANESULPHONATE IN RATS
}

\author{
H. JACKSON, C. MARION JACKSON AND PAMELA JONES \\ Unit of Reproductive Pharmacology, University of Manchester, \\ Manchester M16 8QJ
}

\section{(Received 29th August 1972)}

For the most part, the antifertility actions of non-steroidal chemicals in male rats do not appear directly to involve the endocrine system (Jackson, 1970). In this species, administration of ethylenedimethanesulphonate (EDS) is accompanied by a temporary involution of both the ventral prostate and the seminal vesicles (Cooper \& Jackson, 1970). This observation naturally led to an investigation of how far the antispermatogenic and antifertility actions of this compound involved the endocrine system, particularly the production and secretion of androgen. Treatment with EDS also inhibits the spermatogenic process in the mouse (Cooper \& Jackson, 1970), in Japanese quail (Jones, Kominkova \& Jackson, 1972) and in the parasitic worm, Schistosoma mansoni (Davies \& Jackson, 1970).

After a single dose of the compound $(75 \mathrm{mg} / \mathrm{kg}$ intraperitoneally), rats were sterile by Week 2 and remained thus for about 8 weeks (Table 1); in the great majority, normal fertility was finally restored. The corresponding weekly fertility pattern from male rats given this dose of EDS whilst under a regimen of nine daily injections of testosterone propionate (TP) (3 mg daily subcutaneously, commencing 3 days before the dose of EDS and continuing for 5 days afterwards) indicated some protective action, but only upon post-meiotic cells (Table 1). This is probably related to the androgen dependence in the rat of meiotic and post-meiotic stages of spermatogenesis. Androgen is able to maintain the entire spermatogenic process in hypophysectomized rats (Boccabella, 1963; Neumann \& von Berswordt-Wallrabe, 1966; Clermont \& Harvey, 1967) so that in our experiments, the failure of testosterone to support the pre-meiotic stages against damage by EDS was unexpected. Treatment with TP alone at this dose level is known to produce a 20 to $30 \%$ inhibition of the rat spermatogenic epithelium (Clermont \& Harvey, 1967), presumably through pituitary inhibition. This might have some bearing on the delayed sterilizing action still seen in the EDS - TP experiment although no antifertility effect was seen after TP alone (Table 1). The effect of concurrent gonadotrophin treatment (HCG, Pregnyl, 100 i.u./day subcutaneously for 9 days; EDS given on Day 4) was next examined. This procedure failed to prevent male rats becoming sterile in Weeks 2 to 5 after the dose of EDS, but there was a marked protective action on premeiotic cells so that in most rats, fertility was restored in Week 6 (Table 1). It was strange however, that in both $\mathrm{TP}$ and HCG groups given 
EDS, three of ten male rats were not protected at all, remaining sterile throughout the experiment after siring a normal size litter in Week 1. Although EDS has also been shown to exert a marked antispermatogenic and sterilizing action in Japanese quail (Jones et al., 1972), we have been unable to demonstrate any protective action by either testosterone or HCG in this species.

Table 1. Average weekly offspring from male rats treated with EDS and hormone combinations

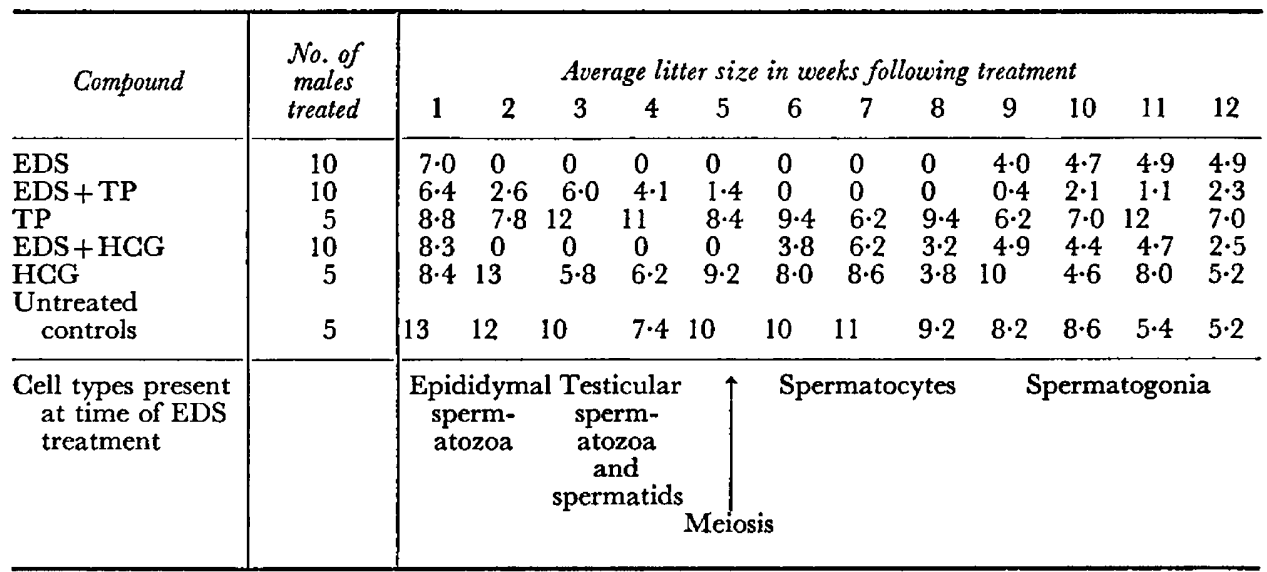

$\mathrm{EDS}=$ ethylenedimethane sulphonate. $\mathrm{TP}=$ testosterone propionate. $\mathrm{HCG}=$ human chorionic gonadotrophin.

Details of dosage are given in the text. The results were obtained from consecutive weekly pairings of male rats; data referring to ten males are a combination of two experiments using five males in each. The antifertility effects can be correlated with damage to spermatogenic cell types present at the time of treatment. Note the protective action of testosterone on spermatids and spermatozoa and of HCG on premeiotic cells, i.e. spermatocytes and spermatogonia.

The histological appearance of the rat testis after these treatments presented some interesting contrasts. Testosterone in EDS-treated rats maintained the weights of the accessory structures and the histology of the testis appeared normal 2 weeks after the dose of the sulphonic ester. Subsequent changes occurred in the seminiferous epithelium which were compatible with the later onset of sterility (Table 1). After the combination of HCG and EDS, apart from the unprotected rats referred to above, the histology of the testis appeared normal throughout although the prostate and seminal vesicle weights were not maintained.

Current knowledge of the hormonal control of spermatogenesis is still unsatisfactory. A long-held view is that FSH promotes spermatogonial proliferation whilst LH supervises the remainder of the process through androgen secretion from the interstitial (Leydig) cells. However, in hypophysectomized rats, an FSH-ICSH preparation (ICSH $=\mathbf{L H}$ ) was shown to prevent testicular atrophy and maintain the accessory glands; concurrent administration of the anti-androgen, cyproterone acetate, inhibited these effects (von BerswordtWallrabe, Steinbeck \& Neumann, 1968) although the interstitial tissue retained a normal appearance. From this study, it appeared that neither of the gonadotrophins alone played a direct rôle in maintaining the spermatogenic process, 
and a number of authors favour a synergistic action of FSH and testosterone; the overall situation has been reviewed recently by Steinberger (1971). In a study with hypophysectomized patients (Mancini, Vilar, Donini \& Pérez Lloret, 1971), neither FSH nor LH adequately stimulated the germinal epithelium, although the combined hormones fully stimulated spermatogenesis provided the ratio favoured LH. In vitro, an effect of FSH on the seminiferous tubules of hypophysectomized rats took the form of an increased level of 3',5' cyclic AMP, possibly due to stimulation of Sertoli cells (Dorrington, Vernon \& Fritz, 1972).

Ethylenedimethanesulphonate is a simple, non-steroidal compound and we have suggested that it interferes with androgen production by the Leydig cells (Cooper \& Jackson, 1970). Since EDS does not inflict histological damage upon the spermatogenic cells in the majority of rats receiving HCG, either the gonadotrophin directly prevents EDS damage or an androgenic mechanism impaired by EDS can still respond to appropriate gonadotrophin stimulation. The fact that the prostate and seminal vesicles of the HCG-EDS-treated animals still undergo involution in the majority of animals favours the former explanation. Experiments in this laboratory using labelled steroids have so far demonstrated a marked and sustained impairment of the ability of testis tissue from EDStreated rats to synthesize testosterone from progesterone (Bu'Lock \& Jackson, 1971/72). With one or two exceptions, this situation remains unaffected in rats also given HCG. It is also not clear why the spermatogenic process in EDStreated animals fails adequately to respond to the exogenous testosterone.

This work was supported by grants from the Ford Foundation and the Medical Research Council.

\section{REFERENCES}

BocCABELlA, A. V. (1963) Reinitiation and restoration of spermatogenesis with testosterone propionate and other hormones after long-term post-hypophysectomy regression period. Endocrinology, 72, 787.

Bu'Lock, D. E. \& JAckson, C. M. (1971/72) Suppression of testicular androgens in the rat by ethylene dimethanesulphonate. Gynecol. Invest. 2, 305.

Glermont, Y. \& Harvey, S. G. (1967) Effects of hormones on spermatogenesis in the rat. Ciba Colloq. Endocr. 16, 173.

COOPER, E. R. A. \& JACkson, H. (1970) Comparative effects of methylene, ethylene and propylene dimethanesulphonates on the male rat reproductive system. F. Reprod. Fert. 23, 103.

Davies, P. \& JAckson, H. (1970) Experimental studies on the chemosterilization of Schistosoma mansoni. Parasitology, 61, 167.

Dorrington, J. H., Vernon, R. G. \& Fritz, I. B. (1972) Effect of gonadotrophins on the 3',5'-AMP levels of seminiferous tubules. Biochem. biophys. Res. Commun. 46, 1523.

JACKson, H. (1970) Antispermatogenic agents. Br. med. Bull. 26, 79.

Jones, P., Kominkova, E. \& JAckson, H. (1972) Effects of antifertility substances on male Japanese quail. 7. Reprod. Fert. 29, 71.

Mancini, R. E., Vilar, O., Donini, P. \& Pérez Lloret, A. (1971) Effect of human urinary FSH and LH on the recovery of spermatogenesis in hypophysectomized patients. F. clin. Endocr. Metab. 33, 888.

NeUmanN, F. \& von Berswordt-WALlRABe, R. (1966) Effects of the androgen antagonist cyproterone acetate on the testicular structure, spermatogenesis and accessory sexual glands of testosteronetreated adult hypophysectomized rats. F. Endocr. 35, 363.

Steingerger, E. (1971) Hormonal control of mammalian spermatogenesis. Physiol. Rev. 51, 1.

von Berswordt-Wallrabe, R., Steinbeck, H. \& Neumann, F. (1968) Effect of FSH on the testicular structure of rats. Endokrinologie, 53, 35. 